Artigo: Diálogos entre direito e gênero: a essencialidade tributária e o uso de bens de higiene pessoal e cuidado na formação da identidade da mulher

\title{
A CRIATIVIDADE NA EDUCAÇÃO JURÍDICA
}

\author{
CREATIVITY IN LEGAL EDUCATION
}

Priscila Pereira Cavalcanti dos Santos*

\begin{abstract}
RESUMO
A pesquisa, que possui campo de estudo em Teoria do Direito, teve por objetivo verificar, através dos métodos de revisão de literatura, estudo de caso e entrevistas, se há instituições de educação jurídica que ainda não adotam métodos capazes de contribuir na formação de profissionais do Direito mais criativos, por se tratar de uma habilidade fundamental na contemporaneidade. Através de entrevistas entre alunos da Pontifícia Universidade Católica de Minas Gerais e Fundação Getúlio Vargas, pôde-se averiguar que, apesar de ter se tratado de uma pesquisa qualitativa, os estudantes da primeira universidade, em sua maioria, afirmaram que a criatividade não foi desenvolvida em sala de aula ao longo do curso. Foram entrevistados também alunos da Pontifícia Universidade Católica de Minas Gerais que fazem parte de grupos de pesquisa ou projetos de extensão com o intuito de verificar de perceberam o desenvolvimento da criatividade nesses espaços. Procurou-se, assim, fomentar o aperfeiçoamento dos cursos jurídicos apresentando algumas metodologias, em especial o ensino do Direito com a Arte.
\end{abstract}

Palavras-chave: Criatividade. Estudo de caso. Educação jurídica. Competências. Direito.

\begin{abstract}
The research, which has a field of study in law theory, aimed to verify, through literature review methods, case study and interviews, if there are legal education institutions that do not yet adopt methods capable of contributing to the training of professionals more creative, because it is a fundamental skill in contemporary times. through interviews with students from the pontifical catholic university of minas gerais and the getúlio vargas foundation, it was found that, despite being a qualitative research, the first university students, for the most part, stated that creativity was not developed in the classroom along the course. also interviewed were students from the pontifical catholic university of minas gerais who are part of research groups or extension projects in order to verify that they perceived the development of creativity in these spaces. the aim was to promote the improvement of legal courses by presenting some methodologies, in particular the teaching of law in conjunction with art.
\end{abstract}

Keywords: Creativity. Case study. Legal education. Skills. Law.

\section{INTRODUÇÃO}

O debate a respeito da metodologia da educação jurídica tem ocorrido há alguns anos. Voltando- se para os dias de hoje, tem-se que os estudantes estão fadados a aprenderem tão somente as leis sem refletirem a respeito delas. A educação jurídica nas universidades se resume a um ato de transmissão de informações genéricas e/ou profissionalizantes, formando alunos

Artigo submetido em 05 de junho de 2021 e aprovado em 07 de setembro de 2021

*Graduanda em Direito pela Pontifícia Universidade Católica de Minas Gerais. E-mail: priscila.pereira.cavalcanti@gmail.com 
que não sabem ao certo o que fazer com esses conhecimentos transmitidos de maneira desarticulada e sem reflexão crítica (FARIA, 1987).

Vários são os pontos críticos do ensino jurídico, o mais importante deles é o fato da formação do bacharel estar baseada em um tecnicismo de saber fazer em detrimento de saber o porquê, com a mera aprendizagem de informações que parecem desvinculadas da prática, apesar de não o serem (FERRAZ JR, 1979).

O objetivo principal deste artigo é averiguar se a criatividade está sendo desenvolvida no curso de Direito da Pontifícia Universidade Católica de Minas Gerais através de estudo de caso e entrevistas com os alunos desta e da Fundação Getúlio Vargas, universidade que possui metodologia diferenciada, segundo revisão bibliográfica. Além disso, serão apresentadas metodologias de ensino, inclusive a que engloba o ensino de direito em conjunto com a arte, com o intuito de formação de juristas mais criativos.

\section{A EDUCAÇÃO JURÍDICA NO BRASIL: BREVE ANÁLISE}

Diferentemente do que ocorrera na colônia espanhola, até 1827, que foi quando foi criado o primeiro curso de Direito no Brasil, a colônia portuguesa carecia de cursos de ensino superior. Isso se explica pelo fato da metrópole recear que a criação de cursos superiores acelerasse o processo emancipatório (VENÂNCIO FILHO, 1978).

A partir da segunda metade do século XVIII, o ensino de Portugal começou a passar por transformações. Abrindo-se as portas para o iluminismo e deixando-se para trás a metodologia escolástica e o ensino voltado para o direito romano, os brasileiros que iam buscar conhecimento na metrópole portuguesa retornavam para a colônia influenciados pela nova cultura que se instalava. A reforma pombalina contribuiu para o abandono do direito romano para um enfoque no direito pátrio, com a adoção dos princípios racionalistas na interpretação das normas jurídicas (VENÂNCIO FILHO, 1978).

Com a independência, o Brasil ainda era carente de uma cultura jurídica. Era uma ciência estudada por uma pequena elite, elite essa responsável pela criação dos cursos jurídicos (VENÂNCIO FILHO, 1978)

Após muita discussão acerca da criação de universidades no Brasil, em 11 de Agosto de 1827 foi convertido em lei o Projeto de Lei para a criação dos cursos em Olinda e São Paulo. Para o funcionamento dos cursos, fez-se necessário que estes fossem abrigados em velhas instituições eclesiásticas e como diz Alberto Venâncio (1982, p. 37), "as dificuldades para o funcionamento eram, porém, de toda ordem, tanto quanto às instalações materiais, tanto quanto ao pessoal". Segundo o autor, os professores, muitas das vezes, tinham que ser portugueses, pela falta de pessoal no país e, citando Tavares de Lira, afirma que alguns não aceitavam as nomeações.

$\mathrm{O}$ bacharel em direito se tornou a figura central de um Estado que erigiu-se como de magistrados, dominado por juízes, tendo em vista que era mediador dos interesses privados e públicos. Além disso, a fundação dos cursos jurídicos pautou-se na mesma mentalidade que norteou os principais movimentos sociais da época, que resultaram no individualismo político e liberalismo econômico constituindo um Estado Nacional que postulou a burocratização do aparelho estatal (ADORNO, 1988).

Assim sendo, um tipo de bacharel voltado para as necessidades e ideais liberais do Estado se formava, como afirma Sérgio Adorno (1988, p. 91): “(...) profissionalizado para concretizar o funcionamento e o controle do aparato administrativo; e habilmente convencido senão da legitimidade, pelo menos da legalidade da forma de governo instaurada".

Quanto a estrutura curricular, esta foi influenciada pelo jus-naturalismo com noções de Direito Público Eclesiástico para se viabilizar a mediação de relações entre o Estado e a Igreja (ADORNO, 1988). 
Artigo: Diálogos entre direito e gênero: a essencialidade tributária e o uso de bens de higiene pessoal e cuidado na formação da identidade da mulher

No final do século XIX, o Brasil começa a passar por um período denominado de "Ilustração Brasileira", em que o país abre as portas para novas ideias, nos dizeres de. Neste período ressalta o cientificismo em sua forma liberal, que reclama a liberdade de ensino, tratase aqui da Reforma do "Ensino Livre". (VENÂNCIO FILHO, 1982).

A experiência do ensino livre no Brasil se baseou em experiências estrangeiras, em uma perspectiva sociológica e pedagógica muito diferente do que acontecia aqui, motivo pelo qual o fato da liberdade de frequência e inexistência de exames parciais constituíram em uma grande fraude de tal movimento (VENÂNCIO FILHO, 1982).

Com a proclamação da República vieram algumas modificações no ensino jurídico, como por exemplo a extinção da cadeira do Direito Eclesiástico da grade curricular em 1890. Além disso, com a Reforma Benjamin Constant, há a criação de cursos livres e faculdades livres em vários estados, quebrando o monopólio São Paulo-Recife. Houve, assim, um sentimento generalizado de que o aparecimento dessas novas instituições foram responsáveis pelo declínio do ensino jurídico, muito embora fora constatado que em nada se diferenciavam do padrão de São Paulo e Recife (VENÂNVIO FILHO, 1979).

Já em 1907, se discutia, no Brasil, sobre a educação jurídica e seu método expositivo com o livro publicado de Aurelino Leal com o título "A Reforma do Ensino do Direito no Brasil", conforme se vê no trecho que se segue:

\footnotetext{
Mas, já ficou mostrado que o ensino da arte jurídica sempre se fez, entre nós, com o método expositivo. O professor, da sua cadeira, prevê e resolve situações jurídicas durante uma hora ou mais, finda a qual dá a lição por concluída. Na conferência seguinte o mesmo fato repete-se. A perda de tempo é grande, o proveito nenhum. Os homens diplomados, isto é, aqueles que se diplomaram em ciências assim ensinadas, sabem perfeitamente que o menor auxiliar que encontraram foram os lentes. Que vale uma lição oral assim proferida? Em sua casa, encontrá-la-á nos compêndios adotados ou nos tratados que tiver. O sistema de pontos usado por quase todos os estudantes é uma prova de que a lição do professor não pôde ficar gravada, o que os leva a escreverem (e, às vezes, com que sacrifício da boa ciência!) os resumos que fazem e que decoram, para o bom êxito dos exames anuais (LEAL apud VENÂNCIO FILHO, 1982, p. 236).
}

A partir de 1931, muito embora não houvesse modificação quanto a metodologia do ensino jurídico, a Reforma Francisco Campos dividiu o curso em bacharelado e doutorado, sendo o primeiro puramente profissional (formação de práticos do direito) e o segundo para a formação de professores. Já em 1962, foi fixado um currículo mínimo com sistemática que em nada se diferenciava daquele de cem anos atrás e apenas em 1972 foi estabelecido um currículo mais flexível e adequado às necessidades da época (VENÂNCIO FILHO, 1979).

\subsection{A crise da educação jurídica}

As inúmeras reformas às grades curriculares dos cursos de Direito são uma constante histórica na educação jurídica que se baseia apenas em acréscimo de conteúdos, implicando na desmotivação dos estudantes (OLIVEIRA, 2017).

Assim sendo, a metodologia voltada para o automatismo com absorção máxima de conteúdo sem reflexão contribui apenas para que o estudante seja funcional. Nos dizeres de Roberto Lyra Filho (1980, p. 8):

Nem nos satisfazem determinadas "modernizações de ensino" cuja finalidade é agilizar o currículo, para servir à ideologia tecnocrática ou ao desenvolvimento capitalista, dependente e atado à dominação multinacional. Isto apenas produz "mão de obra" especializada, para o staff do Estado ou do big business, na mesma estrutura. 
Quero dizer que esse tipo de ensino aliena o estudante e paralisa o esforço de pensar o direito da independência econômica e da liberdade político-social.

Tais reformas não conseguem resolver o problema considerado um dos mais relevantes que é o de ordem pedagógica. $\mathrm{O}$ educando é obrigado a memorizar mecanicamente conteúdos através desse ensino de narrativas, não havendo comunicação entre educando e educador. Segundo o autor, "quanto mais o recipiente for enchido, melhor será o educador; quanto mais dócil for o educando na permissão do enchimento, melhor será o educando" (NUNES, 2005, p. 176). É um sistema de transferência em que o educando memoriza e repete o que é recebido.

Essa questão é abordada por Paulo Freire (1987) em torno de uma concepção bancária, em que o educador narra conteúdos e transmite conhecimentos para que o educando memorize mecanicamente o que é narrado, pois o "saber", neste viés, seria visto como uma doação dos que se julgam sábios aos que julgam nada saber. Em suas palavras, “(...) a educação se torna um ato de depositar, em que os educandos são os depositários e o educador o depositante" (FREIRE, 1987, p. 33). Em síntese, o autor aborda a concepção bancária da seguinte forma:

a) O educador é o que educa; os educandos, os que são educados.

b) O educador é o que sabe; os educandos, os que não sabem.

c) $\mathrm{O}$ educador é o que pensa; os educandos, os pensados.

d) O educador é o que diz a palavra; os educandos, os que a escutam docilmente.

e) O educador é o que disciplina; os educandos, os disciplinados.

f) O educador é o que opta e prescreve sua opção; os educandos os que seguem a prescrição.

g) O educador é o que atua; os educandos, os que têm a ilusão de que atuam, na atuação do educador.

h) O educador escolhe o conteúdo programático; os educandos, jamais ouvidos nesta escolha, se acomodam a ele.

i) O educador identifica a autoridade do saber com sua autoridade funcional, que opõe antagonicamente à liberdade dos educandos; estes devem adaptar-se às determinações daquele.

j) O educador, finalmente, é o sujeito do processo; os educandos, meros objetos. (FREIRE, 1987, p. 34)

Ao longo dos anos, percebe-se que os cursos jurídicos não têm caminhado para uma melhora, muito pelo contrário. Cada vez mais os cursos de Direito se aproximam dos cursinhos, em vez de haver uma formação humanística de profissionais com capacidade crítica (RIZZATTO, 2005). A esse respeito, tem-se, ainda, que "não é papel das corporações ensinar, nem muito menos se transformarem em cursinhos para vestibulandos de exame de ordem" (BASTOS, 1994. p. 51).

Lênio Streck (2011) também aborda a questão afirmando que o ensino jurídico se baseia na antiga cultura de seguir manuais e, "forma-se, assim, um imaginário que 'simplifica' o ensino jurídico, a partir de construções de standards e lugares comuns, repetidos nas salas de aula (...)" (STRECK, 2011, p. 73).

Segundo Luiz Antônio (2005), "o modelo estabelecido nas faculdades ou cursos de direito é arbitrário e sem nenhum sentido científico nem pedagógico. Não faz nem ciência nem se ensina a conhecer. Ele foi estabelecido há décadas e nunca modificado" (NUNES, 2005, p. 178).

Além disso, os estudantes de direito estão fadados a aprenderem conteúdos como se estivessem acabados e como se todos os problemas estivessem resolvidos. O autor Luiz Antônio (2015) traz o exemplo do estudo do Estatuto da Criança e do Adolescente (ECA). Na teoria, neste estatuto todos os problemas estão resolvidos, tendo em vista que este visa a redução de desigualdades e trata do respeito à dignidade dos menores, protegendo-os contra o abuso. $\mathrm{O}$ ECA é estudado de maneira abstrata e não se vê em grandes cidades professores e alunos que 
Artigo: Diálogos entre direito e gênero: a essencialidade tributária e o uso de bens de higiene pessoal e cuidado na formação da identidade da mulher

realmente cuidam desses seres humanos e não se sabe de estudos em que isto efetivamente acontece.

De maneira geral, a universidade tem cumprido cada vez menos a sua função formativa, nos dizeres de José Eduardo Faria (1987), “a ênfase à 'rentabilidade' educacional anulou por completo, assim, a função formativa da Universidade brasileira, mediante uma crescente marginalização das atividades criativas e críticas" (FARIA, 1987, p.18).

Além disso, a pesquisa jurídica deve ser mais valorizada, pois "a pesquisa é o instrumento de aproximação do aluno com sua própria realidade social, judicial, jurisprudencial e bibliográfica" (BASTOS, 1994, p.50).

\title{
3 DAS COMPETÊNCIAS
}

\subsection{A Portaria no 236/2015 do Ministério da Educação (MEC)}

Nesta portaria foram traçadas as diretrizes curriculares para os cursos de Direito. Além disso, é trazido o perfil profissional dos bacharéis esperado, que é aquele mais crítico, reflexivo e criativo, levando em consideração a interdisciplinaridade e o desenvolvimento de competências. Nos dizeres de Pablo Alves de Oliveira (2017):

\begin{abstract}
Percebe-se assim que, além dos conteúdos, a legislação adotou um modelo de competências, revertendo a hegemonia do modelo "conteudista" que fincou tradição na educação jurídica no país. Além disso, as competências e conteúdos atendem aos partidários de concepções não positivistas do Direito, valorizando o estudo de seus fundamentos axiológicos e filosóficos, a reflexão crítica, o estudo dos fenômenos políticos, sociais, econômicos, dentre outros, relevantes na criação, interpretação e aplicação do Direito, bem como os processos de argumentação, tomada de decisões e julgamento (OLIVEIRA, 2017, p. 174).
\end{abstract}

Com o modelo de ensino pautado em memorização de conteúdos e fragmentação dos saberes adotado pelas universidades, gera-se a incapacidade de se formar profissionais competentes para apresentar novas respostas em contextos de incertezas. Isto quer dizer que os profissionais serão inaptos a atuarem em uma sociedade que vive em constante mudança (ROCHA; COSTA, 2013).

\subsection{O conceito de competências}

Diversos são os significados de competência, tendo em vista se tratar de uma palavra comum em diversas áreas. Sendo assim, cada área de conhecimento atribui um significado conforme a problemática a ser enfrentada pela matéria determinada (PERRENOUD, 2013). Segundo Perrenoud (2013):

(...) haverá competência se o ator:

- dominar regularmente um conjunto de situações que possuem a mesma estrutura.

- mobilizar e combinar, para a finalidade em questão, diversos recursos: saberes, relação com o saber, capacidades (ou habilidades), atitudes, valores e identidade;

- apropriar-se de novos recursos ou, se necessário, desenvolvê-los. (Perrenoud, 2013, p. 46).

Assim sendo, o autor define competência como capacidade de agir de maneira eficaz em determinada situação apoiando-se em conhecimento, mas não se prendendo a ele. Portanto, muitas pessoas podem possuir um grande nível de instrução, assim como podem deter vários 
tipos de recursos, mas ainda assim existe a possibilidade de se depararem com uma situação em que não são competentes para resolver.

\section{DA COMPETÊNCIA CRIATIVIDADE}

\subsection{O conceito de criatividade e sua importância}

Apesar de cada pessoa ter para si um conceito de criatividade, é possível correlacionala com solução de problemas e descoberta de oportunidades, ou seja, atos criativos são produtos da ruptura das normas e acabam por promover uma nova realidade (PREDEBON, 2013).

Da mesma forma, Daniel Vargas (2014) traz a definição de criatividade (mas seguindo a linha de criatividade social) como sendo "a capacidade de redesenhar as instituições que organizam a vida em sociedade, para construir novas formas de colaboração que facilitem a solução de problemas sociais (...)" (VARGAS, 2014, p.84). Um dos exemplos trazidos pelo autor:

\footnotetext{
João Joaquim Segundo, ex-padre, residente na periferia de Fortaleza, preocupado com a pobreza extrema que aflige milhares de cidadãos na comunidade Palmas, criou banco que emite e gere uma nova moeda social, que circula apenas na comunidade. $\mathrm{O}$ Palma, como é conhecida essa moeda, é negociado com deságio, para estimular a troca pelo real. Assim, serve como estímulo para enraizar a riqueza gerada pelos habitantes da comunidade e combater a erosão financeira, uma das causas diagnosticadas da pobreza e do subdesenvolvimento local. A experiência local do Banco Palmas estimulou mudanças no ordenamento do Banco Central do Brasil. Hoje, mais de 50 comunidades no Brasil e na América Latina adotam o Palma como instrumento de desenvolvimento. (VARGAS, 2014, p. 84-85)
}

Explica, então, Daniel Vargas (2014), que as inovações institucionais possibilitam a criação de "novos modelos de colaboração para o enfrentamento dos nossos problemas, ampliando o material sobre o qual a sociedade e o estado operam. O fim de sua atividade é resolver um problema" (VARGAS, 2014, p. 85).

Sendo assim, a abordagem da criatividade que se faz necessária para o estudante de Direito é esta que se liga à mobilização de recursos para a resolução de problemas. Nos dizeres de Leonel Severo Rocha citado por Rocha e Costa, "a função dos juristas é postular o direito de inventar ou recriar, constantemente, mecanismos que lhes possibilitem o diálogo com o social (ROCHA apud ROCHA; COSTA, 2013, p. 286).

\subsection{O desenvolvimento da criatividade e outras competências na educação jurídica}

As faculdades, que possuem uma base metodológica associada ao ensino de manuais e conteúdos (características próprias de uma educação baseada em uma concepção bancária), focam em ensinar o aluno a aplicar a lei em caso concreto, e não um profissional preparado para atuar em um mundo complexo (ROCHA; COSTA, 2013).

Luís Alberto Warat surge na segunda metade do século XX e suas reflexões ainda cabem no sistema de educação hoje vivenciado pela cultura jurídica. $\mathrm{O}$ autor criticava o modo como se dava a formação jurídica e denunciava a falta de liberdade e criatividade dos envolvidos no processo educativo. Nas Palavras de Rocha e Costa (2013), "por intermédio de uma perspectiva surrealista do Direito, Warat propôs outra forma de pensar a atividade educativa, pautada na criatividade, na autonomia e na alteridade" (ROCHA; COSTA, 2013). Portanto, o autor tinha como proposta a vinculação do Direito com as demais áreas de conhecimento e acreditava no desenvolvimento da criatividade no Direito através da arte. Tinha o desejo de reinventar o 
Artigo: Diálogos entre direito e gênero: a essencialidade tributária e o uso de bens de higiene pessoal e cuidado na formação da identidade da mulher

ensino jurídico a partir do surrealismo e carnavalização, buscando formas de romper com a racionalidade puramente instrumental através da poesia. Em suas palavras:

Pedagogicamente falando, as artes brindam uma possibilidade insubstituível, estimulam a imaginação criativa, tornando-nos, absolutamente, permeáveis para o novo. Representam atos de produção do novo. É o novo erotizado pelo ato pedagógico. Os cadáveres são poeticamente enterrados. Eros, pedagogo. As verdades nostálgicas, vencidas pela ludicidade da sala de aula. As vanguardas regressivas do academicismo derrotadas por uma pragmática poética, afetiva e eficiente.

Já não se trata de fazer discursos sobre o valor pedagógico de uma imaginação criativa. É coloca-la em prática para deslocar nossa mentalidade do sistema instituído. É fazer a experiência de produção do novo. É aprender a "ser o homem novo" (WARAT, 1990, p. 18).

Com o intuito de gerar um novo curso, a Fundação Getúlio Vargas propõe, algumas práticas pedagógicas e inovações curriculares visando a garantia de formação de profissionais com autonomia intelectual e capacidade para a construção de novos institutos jurídicos (ANCONA, 2013). No currículo da faculdade citada consta a previsão de disciplinas de outras áreas de conhecimento, como "Artes e Direito", implicando na importância desse diálogo para a construção do olhar do operador do direto. Sobre isso comenta José Garcez (2009):

Decorre daí a opção por um curso que deliberadamente não cede ao verbal o lugar de fonte única de apreensão das realidades, mas busca equilibrar diversas formas de expressão artística (artes visuais, música, literatura, arquitetura etc.), como corolário desse entendimento de que o cerne da investigação deve abranger modos plurais de refletir e encenar, artística e juridicamente, matrizes ideológicas (GARCEZ, 2009, p. 218).

A partir do momento que o estudante se depara com uma série de situações representadas no meio artístico e que não são codificadas no ordenamento jurídico, começa-se a abstração, ampliando-se "o repertório de modelos de conceituação de que dispõem para produzir sentidos" (GARCEZ, 2009, p. 218). Ao lecionar a disciplina de "Direito e arte", o professor José Garcez objetiva fazer a união da rigorosidade conceitual com a percepção, permitindo a ampliação e renovação de pensar o Direito. Desta maneira, o ensino de "Direito e arte" objetiva tanto a compreensão maior de outras matérias, assim como o complexo lugar que o Direito ocupa na sociedade. Assim, afirma José Garcez (2015, p. 127):

Por isso, o desenho desse curso de Artes e Direito inclui em sua estruturação, programática e deliberadamente, um amplo conjunto de narrativas em outras linguagens (pintura, música, cinema, teatro, fotografia, grafite, etc.). Espera-se, com isto, que os alunos sejam capazes de expandir tanto sua capacidade de construir matrizes mais sofisticadas de ponderação jurídica, como sua percepção crítica do substrato ideológico que vai implícito em diferentes formas de ponderação.

O professor de "Direito e Ópera”, Gabriel Lacerda (2015, p. 166), afirma:

Visto de outra perspectiva: cada pessoa que tem contato com uma obra de arte percebe-a de uma forma particular, capta-a com seu próprio modo de ser, sua história de vida, seus gostos e suas idiossincrasias, projeta nela frustrações e esperanças, mobiliza suas emoções. Já sobre o direito, geralmente constroem-se teorias, exercitase a razão, procura-se aprender e compreender. Mas quem estuda direito precisa também sentir o direito, posicionar-se diante dele como quem se posiciona diante de uma obra de arte, mobilizando também a emoção, enriquecendo, com a intuição e a sensibilidade, o raciocínio lógico. Localizar o direito nos enredos das óperas e captar 
como a música que acompanha as palavras lhes acentua o significado, pode talvez ajudar também a desenvolver essa capacidade.

Segundo Rocha e Costa (2013), o modelo educacional adotado atualmente é incapaz de sanar as necessidades da sociedade "que exige um profissional competente para apresentar novas respostas em contextos de incertezas" (ROCHA; COSTA, 2013, p. 273). Deste modo, o professor André Rodrigues (2009) ao pensar na questão de competências utilizou-se da disciplina de "Direito e arte" para abordar o tema da interpretação contratual por acreditar que isso "potencializaria a capacidade de estabelecer conexões, o que, por sua vez, permitiria aos alunos compreender $\mathrm{o}$ ato de interpretar um contrato de maneira mais abrangente" (RODRIGUES, 2009), havendo, desta maneira, um atentamento para outros contextos de determinada realidade.

Deste modo, o professor incentivou a apresentação de novas interpretações dadas pelos estudantes, em vez de apenas reproduzir regras e teorias acerca delas, não desprezando todo o seu contexto.

Existem, ainda, várias metodologias ditas como participativas em que incluem o aluno no processo de aprendizagem. Há alguns exemplos utilizados pela Fundação Getúlio Vargas a serem citados e conceituados brevemente. A começar pelo método de "clínica de Direito", Flávia Scarbin e Thiago Acca (2009) afirmam que "consiste na proposta de solução de um conflito jurídico real a partir da representação de causas ou clientes sob a supervisão de um professor" (SCARBIN; ACCA, 2009, p. 2-3).

Já a metodologia do "Debate", Daniel Monteiro Peixoto (2009) conceitua e coloca como objetivo principal a instigação da participação do aluno, levando-o a participar do processo de aprendizado, exercitando o raciocínio.

O método do "Diálogo Socrático", segundo Leonardo Arquimimo de Carvalho (2009) é um mecanismo retórico que utiliza de interação dialogada no formato de perguntas e respostas estimulando a compreensão e reflexão sobre determinado tema.

Por sua vez, o "Método do Caso", segundo Luciana de Oliveira e Vivian Cristina (2009), diz respeito a análise de decisões para o desenvolvimento de raciocínio jurídico, enfatizando a fundamentação e argumentos da solução proposta. Como vantagens para essa metodologia as autoras apresentam a familiarização do estudante com a linguagem e o vocabulário jurídico, a verificação de como foram construídos os argumentos e desenvolvimento da capacidade de construção de raciocínio jurídico, estimulando o senso crítico.

Em outro âmbito, o "Role-Play", segundo Gabbay e Sica (2009) "é o método de ensino por meio do qual o aluno assume um papel e desenvolve, a partir dele, atividades dinâmicas planejadas em relação a determinado tema" (GABBAY; SICA, 2009, p. 73). Através desse método poderão ser desenvolvidas as habilidades de trabalho em equipe, técnicas de negociação, atuação estratégica, dentre outras.

Por fim, o método do "Seminário", segundo Machado e Barbieri (2009), é uma atividade que visa o aprofundamento e reflexão de algum tema proposto pelo professor e o resultado disso não são respostas certas, mas sim suas próprias interpretações. Leva em consideração a investigação, tendo em vista que o intuito desse método é fazer com que os estudantes se reúnam previamente para discutir o assunto proposto para que seja exposto em momento posterior.

\subsection{Estudo de caso: PUC Minas x FGV-Rio}

No total, foram obtidas 111 (cento e onze) respostas aos questionários aplicados às duas instituições. Foram feitas quatro perguntas ao primeiro e quinto períodos da Faculdade de Direito da Pontifícia Universidade Católica de Minas Gerais: 
Artigo: Diálogos entre direito e gênero: a essencialidade tributária e o uso de bens de higiene pessoal e cuidado na formação da identidade da mulher

Em sua opinião, o que é criatividade no Direito?

Você se considera uma pessoa criativa? Por quê?

Você acha que a criatividade é importante no curso de direito? Por quê?

Você acha que a criatividade está sendo desenvolvida no curso ou que ainda será desenvolvida nos próximos períodos? Por quê?

A escolha pelo primeiro período do curso para a aplicação do questionário foi com o objetivo de conhecer as expectativas dos estudantes e suas motivações pessoais, bem como para averiguar o entendimento dos alunos por "criatividade na educação jurídica". A opção pelos alunos do quinto período se deu para averiguar se no intervalo desses dois anos e meio o curso se mostrou mais dogmático ou se fomentou a criatividade em algum momento, averiguando também as expectativas para os próximos períodos e o conceito de criatividade.

Aos alunos do $10^{\circ}$ período e aos egressos da Fundação Getúlio Vargas foram feitas as mesmas perguntas com o acréscimo da seguinte: "você acha que será necessário ser criativo em sua carreira? ". O acréscimo desta pergunta se deu pelo fato de se esperar que os alunos do último período (e também os egressos) poderiam fazer uma avaliação geral de tudo o que estudaram (e o modo como foi estudado) durante todos os anos em que estiveram na universidade.

Foram realizadas, ainda, as seguintes perguntas a alunos participantes de atividades extracurriculares (pesquisa e extensão) com o intuito de averiguar se tais atividades contribuem para o desenvolvimento da criatividade:

Você acha que o Grupo de Pesquisa e/ou Projeto de extensão no qual está inserido(a) tem contribuído ou contribuirá para o desenvolvimento da criatividade?

Você acha que o curso (em sala de aula) tem contribuído para o desenvolvimento da criatividade? Por quê?

A partir da revisão bibliográfica realizada, pôde-se atestar que a Fundação Getúlio Vargas possui metodologias diferenciadas voltadas para o estímulo da criatividade. Assim, optou-se por escolher alunos que se formaram nesta instituição para aplicar o questionário. Os alunos da Pontifícia Universidade Católica de Minas Gerais foram escolhidos partindo-se da hipótese inicial de que a criatividade dos alunos desta universidade não é desenvolvida ao longo do curso.

A divulgação dos nomes dos alunos não será realizada, apenas será feita a identificação do gênero (aluno/aluna), da idade e do período.

\subsubsection{Análise das respostas aos questionários}

A começar pela análise das respostas dadas pelos estudantes no que se refere ao conceito de criatividade, alguns estudantes apostam na ideia da metodologia da educação jurídica aliada com outras áreas de conhecimento:

"É saber passar informações de forma didática, alcançando ao máximo possível a compreensão dos alunos, porém buscando inovar e fugir de uma aula maçante, monótona e extremamente tradicional. Humor, filmes, músicas e curiosidades são formas de fazê-lo". (Aluna, 18 anos, $1^{\circ}$ período)

"Todo conhecimento do mundo pode influenciar no Direito e fazer despertar ápices/acessos criativos. $\mathrm{O}$ direito é muito mais do que a simples leitura dos textos jurídicos, necessita de uma devida interpretação e para que isso seja feito, é preciso 
relativo conhecimento do mundo (e quanto mais conhecimento, melhor)". (Aluno, 19 anos, $1^{\circ}$ período)

Quanto à pergunta sobre a criatividade ter sido desenvolvida no curso de Direito, a maior parte dos alunos do décimo período da Pontifícia Universidade Católica de Minas Gerais entrevistados afirmaram que a competência foi pouco ou não foi desenvolvida (trinta alunos de quarenta e quatro entrevistados). Por sua vez, em resposta à mesma pergunta, a maior parte dos egressos da Fundação Getúlio Vargas afirmou que o curso contribuiu para o desenvolvimento da criatividade (treze pessoas de dezesseis entrevistados). Para melhor visualização, seguem gráficos ilustrativos:

\section{A criatividade foi desenvolvida em sala de aula no curso de Direito da PUC Minas? \\ A criatividade foi desenvolvida em sala de aula no curso de Direito da PUC}

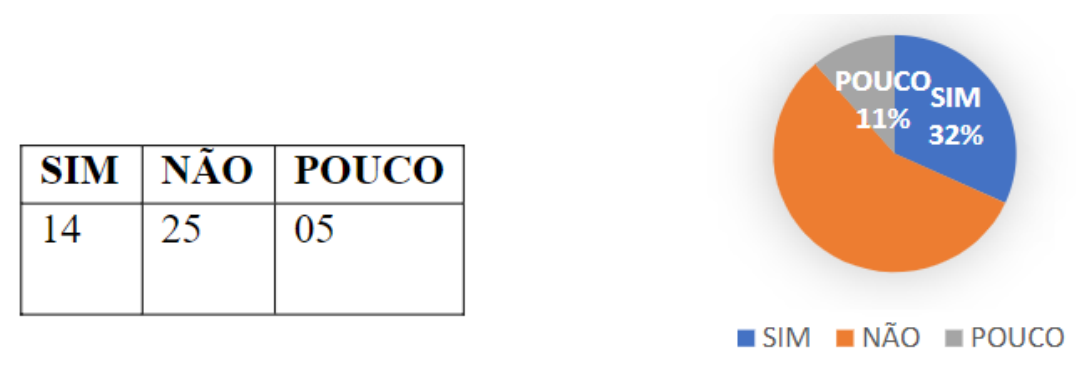

Fonte: elaborado pela autora

\section{A criatividade foi desenvolvida no curso de Direito da FGV-Rio?}

\begin{tabular}{|l|l|l|}
\hline SIM & NÃO & $\begin{array}{l}\text { MAIS } \\
\text { OU } \\
\text { MENOS }\end{array}$ \\
\hline 12 & 03 & 01 \\
\hline
\end{tabular}

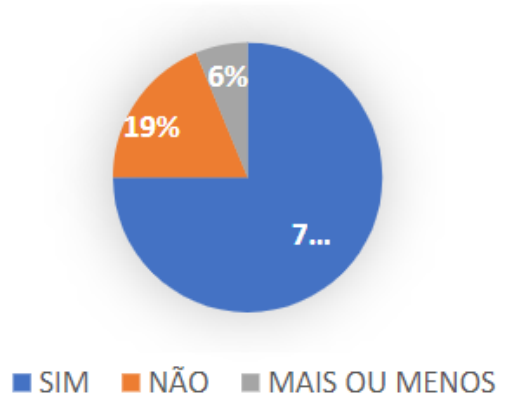

Fonte: elaborado pela autora

Algumas das principais críticas ao ensino apontadas pelos alunos do décimo período:

“[O curso] nos ensina a ser funcionais". (Aluna, 23 anos)

“O curso é dado com base no estudo do direito positivo, sem incentivo a extensão e pesquisa. Não incentivando o pensamento jurídico criativo”(Aluna, 22 anos).

"O curso de direito é um dos menos criativos. Não se desenvolve atividades que façam os alunos serem criativos". (Aluna, 23 anos)

“(...) o volume de matérias transferido na graduação dificulta o estudo aprofundado". (Aluno, 24 anos). 
Artigo: Diálogos entre direito e gênero: a essencialidade tributária e o uso de bens de higiene pessoal e cuidado na formação da identidade da mulher

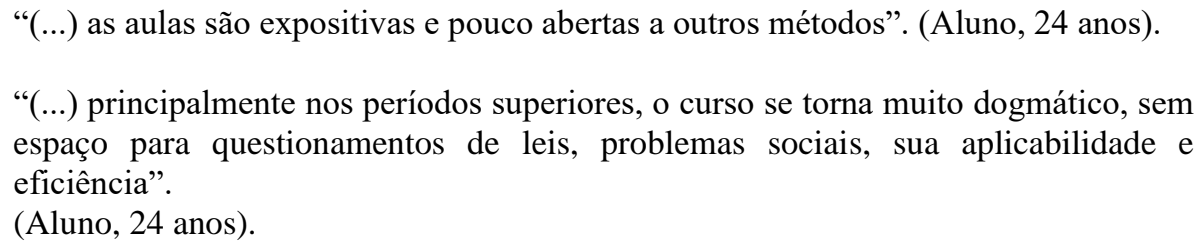

Partindo-se para as respostas dadas pelos alunos participantes de atividades extracurriculares, tem-se que, a maior parte deles afirma que tais atividades contribuem para o desenvolvimento da criatividade, mas que o ensino em sala de aula não contribui. Abaixo, temse algumas das respostas obtidas:

Eu participei de um projeto de extensão por 2 anos, e ele me transformou totalmente. Até porque é um projeto que você tem que lidar com situações inimagináveis. Quanto aos grupos de pesquisa, eu acredito que eles contribuem para o desenvolvimento também, pois te fazem pensar em diversas questões que precisam de uma resposta. Mas eu acho que o projeto e os grupos de pesquisa contribuíram de forma mais significante, porque os professores inseridos têm uma visão diferenciada dos demais. (Aluna, 20 anos).

Acho que o curso de direito vem se rendendo a uma forma mercadológica de ensino, na qual passar na OAB é mais importante que discutir o Direito em si. Sem falar que a busca por aprovações em concurso e/ou em OAB deixa o curso tão técnico e dogmático, que a gente perde a capacidade de abstrair/ser criativo. (Aluno, 24 anos).

Com exceção de algumas poucas aulas ministradas por professores diferenciados. As aulas são, em maioria, tediosas e não despertam o mínimo de interesse, muito porque alguns professores buscam apenas se projetar com a docência e não têm comprometimento, bem como dão aulas de forma mecânica e sem visão crítica. Há também muito desinteresse dos alunos, que acaba repercutindo nos professores, porque os estudantes querem só passar sem assimilar de verdade o conteúdo pensando que, um dia, aprenderão a fundo se for necessário. (Aluno, 24 anos)

Sempre me interessei pelo novo, pela arte e pela criação. Hoje me sinto um pouco cerceado pela dogmática trazida na graduação de direito, que de certa forma coibiu um pouco meu viés criativo, que encontrei valorização apenas das práticas extensionistas das quais participei”. (Aluno, 23 anos)

Em alguns momentos acredito que o curso nos força a ser criativos, como nos projetos de pesquisa, no júri simulado, nas aulas práticas. Porém, considero que ainda é pouca a exigência dessa criatividade". (Aluna, 23 anos).

Por fim, será feita a análise das respostas dadas pelos egressos da Fundação Getúlio Vargas para que se saiba o motivo pelo qual a maioria dos alunos considera que o curso colaborou para o desenvolvimento da criatividade:

"Fomos incentivados ao máximo a pensar e refletir além do estudo das leis propriamente ditas". (Ex-aluna, 23 anos)

"Ao estudarmos matérias pouco convencionais nos cursos tradicionais de direito, acabamos abrindo o nosso leque de conhecimento o que, consequentemente, faz que consigamos olhar para os problemas sob diversas perspectivas". (Ex-aluna, 22 anos)

"(...) temos uma boa base teórica que destrincha todas as formas de interpretação da lei, bem como os seus vieses. Além disso, as diferentes aulas ensinam várias formas de pensar sobre questões jurídicas. E temos até formação de como levar variáveis concretas, por exemplo, econômicas, em consideração de forma confiável. Assim, 
somos apresentados a várias formas de interpretar. (...) A faculdade trabalha mais a forma de pensar do que dá conhecimento geral sobre a questão”. (Aluno, 22 anos).

"A FGV é uma escola que quer que os alunos pensem e reflitam sobre diversas questões sociais, políticas e jurídicas. Com certeza, se destaca por isso”. (Ex-aluna, 22 anos).

"O curso da FGV é bem interdisciplinar, o que implica em uma visão mais ampla da sociedade e do direito". (Ex-aluno, 23 anos).

Os principais argumentos utilizados pelos ex-alunos da Fundação Getúlio Vargas para justificar o desenvolvimento da criatividade foram a interdisciplinaridade e o incentivo à reflexão não se prendendo à dogmática.

\section{CONCLUSÃO}

Atualmente, a educação jurídica continua se pautando em um modelo de séculos atrás. Isto quer dizer que ele se mostra falho para formar profissionais de Direito que atendam as demandas da sociedade, que se diversificam cada vez mais.

Ainda que não seja possível que o Direito resolva todos os problemas da sociedade, ele possui um potencial de contribuição social muito maior do que o apresentado atualmente, já que os alunos poderiam ser muito mais críticos, sensíveis e criativos. Uma vez que a educação jurídica se pauta em uma concepção bancária em sala de aula, tal situação dificulta para que o aluno desenvolva competências.

Sendo assim, os estudantes de Direito, como sujeitos pertencentes ao universo da educação jurídica, devem participar, de fato, dessa educação. A sociedade precisa de juristas criativos capazes de resolver problemas, uma vez que a mutabilidade daquela é acelerada e o jurista deve estar preparado para situações diversas, adversas e novas. Essa contribuição é possível a partir do momento que a educação jurídica for libertadora, alterando o paradigma de ensino até hoje praticado no país.

\section{REFERÊNCIAS}

ADORNO, Sérgio. Os aprendizes do poder: o bacharelismo liberal na política brasileira. Rio de Janeiro: Paz e Terra, 1988.

BASTOS, Aurélio Wander. A crise Brasileira e perspectivas do ensino jurídico. Revista Jurídica: Faculdade de Direito PUCCAMP. Campinas (SP), v. 10, p. 42-52, 1994. ISSN 01035622. Brasília-DF, 12 de jun. p. 24, 2015.

CARVALHO, Leonardo Arquimimo de. Diálogo Socrático. In: GHIRARDI, José Garcez (Org.). Métodos de ensino em direito: conceitos para um debate. São Paulo: Saraiva, 2009

FARIA, Adriana Ancona. A formação de novas competências: articulação da grade curricular e de metodologias participativas no curso da DIREITO GV. In: COUTO, Mônica Bonetti; SANCHES, Samyra Haydêe Dal Farra Naspolini; SILVEIRA, Vladmir Oliveira da (Org.). Educação Jurídica. São Paulo: Saraiva, 2013.

FARIA. José Eduardo. A Reforma do Ensino Jurídico. Porto Alegre: Fabris, 1987. 
FREIRE, Paulo. Pedagogia do Oprimido. Rio de Janeiro: Paz e Terra, 1987.

GABBAY, Daniela Monteiro; SICA, Ligia Paula Pires Pinto. Role-Play. In: GHIRARDI, José Garcez (Org.). Métodos de ensino em direito: conceitos para um debate. São Paulo: Saraiva, 2009

GARCEZ, José. Artes e Direito: as construções do sentido. In: GHIRARDI, José Garcez; VANZELLA, Rafael Domingos Falardo (Org.). Ensino Jurídico Participativo: construção de programas, experiências didáticas. São Paulo: Saraiva, 2009. p.p. 213-221.

GARCEZ, José. Se uma noite de inverno: ensinando Artes e Direito, em Pedro Fortes (ed), Ensino Jurídico e Cultura Pop, Rio de Janeiro: FGV (2015), Volume 11 da série Cadernos FGV Direito Rio.

INSTITUTO NACIONAL DE ESTUDOS E PESQUISAS EDUCACIONAIS ANÍSIO TEIXEIRA. Portaria n. 236, de 10 de junho de 2015. Diário Oficial da União, Brasília-DF, 12 de jun. p. 24, 2015.

JUNIOR, Tércio Sampaio Ferraz. O ensino jurídico. Encontros da UnB. Ensino Jurídico, Brasília, p.67-71, 1978-1979.

LACERDA, Gabriel. Direito e ópera: estímulos a uma percepção sensível do Direito, em Pedro Fortes (ed), Ensino Jurídico e Cultura Pop, Rio de Janeiro: FGV (2015), Volume 11 da série Cadernos FGV DIREITO RIO.

LYRA FILHO, Roberto. O direito que se ensina errado. Brasília: Centro Acadêmico de Direito da UNB, 1980.

MACHADO, Ana Mara França; BARBIERI, Catarina Helena Cortada. Seminário. In: GHIRARDI, José Garcez (Org.). Métodos de ensino em direito: conceitos para um debate. São Paulo: Saraiva, 2009

NUNES, Rizzatto. Apontamentos para uma crítica à Pedagogia no curso de Direito. Revista do Instituto de Hermenêutica Jurídica, Porto Alegre, n.3, p.175-194, 2005. ISSN 1678-1864.

OLIVEIRA, Pablo Alves de. O ódio à educação e a democratização radical da educação jurídica através da aprendizagem mediada significativa: proposta de um novo modelo para os cursos de Direito (Ou como transformar a sala de aula numa mesa de bar?). 2017. 281 f. Tese (Doutorado) - Programa de Pós-Graduação em Direito, Pontifícia Universidade Católica de Minas Gerais, Belo Horizonte, 2017.

PEARSON EDUCATION DO BRASIL. Criatividade e Inovação. Academia Pearson. São Paulo : Pearson Prentice Hall, 2011.

PEIXOTO, Daniel Monteiro. Debate. In: GHIRARDI, José Garcez (Org.). Métodos de ensino em direito: conceitos para um debate. São Paulo: Saraiva, 2009 
PERRENOUD, Philippe. Desenvolver competências ou ensinar saberes? A escola que prepara para a vida. Porto Alegre: Penso, 2013.

PREDEBON, José. Criatividade: abrindo o lado inovador da mente. 8 ed. São Paulo: Pearson Education do Brasil, 2013.

RAMOS, Luciana de Oliveira; SCHORSCHER, Vivian Cristina. Método do caso. In: GHIRARDI, José Garcez (Org.). Métodos de ensino em direito: conceitos para um debate. São Paulo: Saraiva, 2009

ROCHA, Leonel Severo; COSTA, Bárbara Silva. Ensino do Direito e Percepção Discentes: contribuições Waratianas para a construção da pedagogia do novo. In: COUTO, Mônica Bonetti; SANCHES, Samyra Haydêe Dal Farra Naspolini; SILVEIRA, Vladmir Oliveira da (Org.). Educação Jurídica. São Paulo: Saraiva, 2013.

RODRIGUES, André. Por que privilegiar o desenvolvimento de competências? Relato de uma aula de Direito Contratual. In: GHIRARDI, José Garcez; VANZELLA, Rafael Domingos Falardo (Org.). Ensino Jurídico Participativo: construção de programas, experiências didáticas. São Paulo: Saraiva, 2009. p.p. 27-72.

SCABIN, Flávia; ACCA, Thiago. Clínica e Direito. In: GHIRARDI, José Garcez (Org.). Métodos de ensino em direito: conceitos para um debate. São Paulo: Saraiva, 2009

STRECK, Lênio. Hermenêutica Jurídica e(m) crise: uma exploração hermenêutica da construção do Direito. Porto Alegre: Livraria do Advogado, 2014.

VARGAS, Daniel. Jurista Criativo. Cadernos FGV Direito Rio, vol. 9, 2014. pp 83-104.

VENÂNCIO FILHO, Alberto. Análise histórica do Ensino Jurídico no Brasil. Encontros da UnB. Ensino Jurídico, Brasília, p.9-35, 1978-1979.

VENANCIO FILHO, Alberto. Das arcadas ao bacharelismo. São Paulo: Perspectiva, 1982.

WARAT, Luis Alberto. Manifestos para uma ecologia do desejo. São Paulo: Acadêmica, 1990. 